\title{
Cardiovascular System Findings Derived Flag
}

National Cancer Institute

\section{Source}

National Cancer Institute. Cardiovascular System Findings Derived Flag. NCI Thesaurus.

Code $C 124036$.

An indication or description that cardiovascular system data is a derived value. 